\title{
Title: The benefits of gaining research experience through secondment
}

\author{
AUTHOR 1 (corresponding author) \\ Tracey Rose \\ Community Learning Disabilities Nurse (BSc Hons) \\ Telephone: 03000412585 \\ Email: tracey.rose5@nhs.net \\ South West Kent Learning Disabilities Team \\ Kent Community Health Foundation Trust
}

\section{AUTHOR 2 \\ Irene Tuffrey-Wijne (Associate Professor in Intellectual Disability and Palliative Care) \\ I.Tuffrey-Wijne@sgul.kingston.ac.uk}

\section{Abstract:}

This paper describes one learning disability nurse's experience of being seconded to work on a research project in a university setting. The nurse (Tracey Rose) and her academic manager (Irene Tuffrey-Wijne) argue that the benefits of such a secondment go beyond the obvious advantages for the nurse, who will gain valuable research skills. The delivery of evidence-based care and support is enhanced when learning disability nurses are engaged in research. Creating opportunities for a secondment can support nurses' career progression and may promote staff retention. For the academic partner, a close link with clinical practice can keep the research grounded and can help to clarify the impact of research on practice. The authors also discuss the challenges in making such a secondment work.

\section{Introduction}

"It's all about me!" This tongue in cheek comment can frequently be heard in the nursing office. After all unhappy nurses are not effective nurses. This comment has led me to reflect upon and share my recent experience as a seconded nurse research assistant, whilst taking into account the importance of research in this field of nursing.

What relevance does this have? I'd begun to consider my career path. I had completed a preceptorship programme and mentorship course and was now looking for a new challenge and an 
Rose, T. \& Tuffrey-Wijne, I.

The benefits of gaining research experience through secondment Accepted for publication in Learning Disability Practice on $12^{\text {th }}$ December 2016 - This is not the version of record. Published version at http://journals.rcni.com/doi/10.7748/ldp.2017.e1800

opportunity to develop my skills. I receive regular supervision and appraisals; these provide the opportunity to seek direction on both my professional and personal development.

The question at this point was: Where do I want to go? What do I want to achieve from my career? During nurse training my professional development had been prescribed; now as a qualified learning disabilities nurse for 18 months it was my responsibility to identify how I want to progress professionally. I questioned if I should consider a change of job. Participating in a secondment seemed an ideal opportunity. Ideally I wanted to develop my skills in research. How would I find a suitable secondment? Fortuitously, an opportunity arose for a seconded post as a part-time nurse research assistant at Kingston \& St George's, University of London.

\footnotetext{
Case Study - About Me (Tracey's experience)

I am employed as a full time band 5 community learning disabilities nurse with the Kent Community Health Foundation Trust (KCHFT). Through regular supervision and reflection I decided that I would like to further develop my skills and knowledge in research.
}

Knowing that there is very limited research in the field of learning disability, I thought this would be difficult to achieve and costly to KCHFT. Within weeks I had the opportunity to apply for a secondment for a nurse research assistant at Kingston University. The opportunity was a part-time post for three months at a band 6 level working with Dr Irene Tuffrey-Wijne. I came across the advert for the post through the Palliative Care for People with Learning Disabilities network (PCPLD). I have frequently read and incorporated Irene's research and recommendations into study and practice. During the secondment period I would continue to work two days a week in my community nurse role for KCHFT.

The research assistant post required me to recruit and liaise with participants for an interview study. The topic of the research required compassion, empathy, excellent communication skill and professionalism. The nursing skills, gained through carrying out many holistic assessments, were beneficial and imperative for the analysing and gathering of data. However, my previous career history as a secretary/PA was also unexpectedly useful as I needed to be resourceful, organised and IT literate to type up transcripts and use the research analysis software.

When considering the researcher role, I had to think about the cost and time of travelling to South 
Rose, T. \& Tuffrey-Wijne, I.

The benefits of gaining research experience through secondment Accepted for publication in Learning Disability Practice on $12^{\text {th }}$ December 2016 - This is not the version of record. Published version at http://journals.rcni.com/doi/10.7748/ldp.2017.e1800

London from Kent and the pressure this could have on my family. I also felt a huge responsibility to prove myself when learning a completely new role in a short time. It was a challenge to juggle two very different jobs. I also considered the impact on my colleagues and clients. Working within two very different roles and being resourceful with time, money and energy could be a potential barrier to a productive and successful placement. This would require me to manage my personal and professional responsibilities extremely effectively.

At the start of the secondment, Irene and I developed set objectives which were both important to me personally and for the research role. These were reviewed weekly and developed throughout the seconded period. These meetings allowed us to communicate and share thoughts about the emerging themes of the research, concerns and achievements. We monitored the pace of the project and my personal development. During supervision periods in both posts I could identify and reflect on the strengthening of my transferrable skills.

The research topic required me to interview support care staff on how to communicate death related bad news to people with learning disabilities. When interviewing the staff it could be difficult not to console, offer advice and recommend interventions, particularly when people became emotional. After all, this was what I would automatically do as a community nurse. I could empathise with how they were feeling. At times it would be difficult to focus on death and dying so intensely.

During the secondment in my community nurse role I was supporting a person with end of life care. It could be hard to remain professional and at times not let the emotional strain from both roles overcome me. I was given time to reflect with my colleagues and frequent supervision, including support to identify and manage these feelings in both roles. Initially, I did find it very difficult to switch off from one job to the other. As the secondment advanced I became more confident and my professional and personal expectations developed.

A huge challenge was waiting for approval for the research from the Ethics Committee, which took longer than anticipated ${ }_{2}$ also the recruitment of participants for the study. This was frustrating and required patience and flexibility. I negotiated with my Trust and adapted my seconded days from three days a week for three months for the research role to one to two days a week for a while; this 
Rose, T. \& Tuffrey-Wijne, I.

The benefits of gaining research experience through secondment

Accepted for publication in Learning Disability Practice on $12^{\text {th }}$ December 2016 - This is not the version of record. Published version at http://journals.rcni.com/doi/10.7748/Idp.2017.e1800

meant that I could extend the period of secondment to meet the needs of the study because of the delays.

During the seconded time I had a wealth of opportunities to develop my skills. I helped Irene develop, host and present on three training days for staff who work in learning disability services.

The training focused on the study topic, the un-published results and breaking bad news. I attended a Palliative Care Conference as a delegate and joined a research meeting at the House of Lords.

During this time I felt supported, encouraged, and more confident both professionally and personally.

Whilst working for two organisations it was not straight-forward to arrange the personnel and payroll. Some of the logistical HR issues were problematic and needed time, patience, many emails and conversations between various parties to resolve. This problem did, unfortunately, take some shine from an otherwise positive experience. Once the study was submitted I could be more flexible with the days spent on secondment. It felt strange, however, to reintroduce myself more permanently to my community work place; there were changes to the team and new technology introduced to the community health teams.

The secondment was an exciting roller-coaster of emotions. I experienced fatigue and exhilaration, frustration and pride, accomplishment and worry. I have personally identified how in-depth, important and skilled nursing research is and most importantly, how much time is required for gathering and analysing information. How exciting it is to get your work published. We have submitted one paper for publication and are working on another. I recognise how much I enjoy the clinical role of a nurse and the importance of good quality evidence base to support clinical knowledge. You cannot have one without the other. To undertake research is extremely challenging, it was exceptionally rewarding and I am extremely grateful to have had the invaluable experience to develop as a clinician and personally.

\section{Secondment}

There is very little published data available for healthcare professionals and nurses both in the UK and internationally which relate to secondments in healthcare or educational settings. Reports of secondments first being implemented in the health service were primarily introduced only at senior manager level in the 1990's (Hamilton \& Wilkie 2001). 
Rose, T. \& Tuffrey-Wijne, I.

The benefits of gaining research experience through secondment Accepted for publication in Learning Disability Practice on $12^{\text {th }}$ December 2016 - This is not the version of record. Published version at http://journals.rcni.com/doi/10.7748/ldp.2017.e1800

It also appears that there are limited opportunities for career development for nurses which bring together clinical practice and research. Therefore, a secondment can offer a one-off opportunity for an employee to progress professionally and to develop partnership working between organisations (Dryden \& Rice 2008). Work based education has been acknowledged as an effective way to meet the needs of health workers in co-ordinating the requirements of the currently developing health service (Clarke \& Copeland 2003). Secondments are identified as an effective way of contributing to individuals' and to organisational structures with regards to career development (Hamilton \&Wilkie 2001). Therefore, this also benefits the employer by building partnerships, in my case between health and education.

When embarking on a secondment, both the secondee and seconder need to be very clear what this will involve. As a secondee you will remain employed by your initial Trust/employer. The seconder is required to reimburse your employer for your salary which will be paid in the usual way to you. Your employer and seconder both need to be clear who is responsible for other costs, charges or overheads. A job will remain open for you and clear strategies, guidelines, expectations and obligations need to be agreed between all parties (Dryden \& Rice 2008).

It is a concern that there is a reported decline in the recruitment and retention of learning disability nurses in comparison with other branches of nursing (Royal College of Nursing (RCN) 2015). A secondment is recommended as a valuable opportunity for employee development, which in return will aid with staff retention (Dryden \& Rice 2008). A secondment also allows for intra and interprofessional working, whilst developing multi-qualified nurses who will in return be able to work across different care boundaries, becoming more skilled with care delivery (Thomas \& Hynes 2009).

\section{Case Study - Seconding - Irene's Experience}

"Ideally, this role is suited to a practice-based professional who would like to develop his/her research and interviewing skills and therefore we would consider a secondment."

This is what I wrote in the job advert. I had obtained some funding for a short research project and needed a part-time research assistant for just three months. The idea of opening it up as a possible secondment was not just because I thought that it might be difficult otherwise to persuade anyone to take such a short-term position. It was mostly because, for this particular project, I wanted someone with clinical skills (read: excellent communication skills) and insight into the 'real' world of learning disability services. My research assistant would need to interview support staff about issues 
Rose, T. \& Tuffrey-Wijne, I.

The benefits of gaining research experience through secondment Accepted for publication in Learning Disability Practice on $12^{\text {th }}$ December 2016 - This is not the version of record. Published version at http://journals.rcni.com/doi/10.7748/ldp.2017.e1800

\begin{abstract}
related to death, dying and bereavement. She (it turned out to be a 'she') would need to be able to build a quick rapport and convey empathy. "Your clinical experience", the job advert therefore read, "should include working with people who have been bereaved."
\end{abstract}

"You should have some knowledge and experience of research interviews (e.g. through completing a BSC)," it went on, "although we can help you develop these further."

Of course, this was a risk. Would my research assistant be able to draw out the right information from our research participants? But I reckoned that, unlike those all-important communication skills and the ease with being in a clinical environment that comes from experience, I could supervise her just enough to be able to conduct research interviews. So we took the plunge and appointed Tracey, who stood out with her commitment, enthusiasm and organisational skills. It is important that a research interviewer is 'likeable', and she certainly is.

Doing research interviews is not as easy as it sounds, and there are particular challenges for handson nurses. I know; I have been there. I worked in learning disability and palliative care settings for many years before becoming a researcher. It can be particularly difficult to not step in and offer advice or support. Unlike a nurse, a researcher is not there to solve anything - she just needs to listen and take note, and then walk away. It took me years to learn when it is necessary to intervene and 'do' something (occasionally it is, but most of the time it isn't). But once you've got over that hurdle, you begin to realise how much freedom this gives both you and the interviewee, and what a privilege it is that people tell you things they wouldn't tell their manager - or their nurse! Tracey needed a lot of supervision, but she learnt fast. I listened to all her audio-recorded interviews and gave her detailed feedback. She was a delight to work with, because she was so keen to hear all feedback, including my hints and tips for improvement.

There is a huge advantage in engaging practising nurses in research. Tracey brought a real 'buzz' with her, an excitement about doing something that had relevance for her clinical practice. It is extremely helpful for university-based researchers to be reminded of this connection between their work and the 'real world'. Listening to how Tracey and her colleagues dealt with the issues we were researching opened the door to new ideas about how to make our research relevant. Researchers can never have too many links with clinical practice. An added bonus is that in future, I know where 
Rose, T. \& Tuffrey-Wijne, I.

The benefits of gaining research experience through secondment

Accepted for publication in Learning Disability Practice on $12^{\text {th }}$ December 2016 - This is not the version of record. Published version at http://journals.rcni.com/doi/10.7748/ldp.2017.e1800

to go if I'm looking for research participants or research collaborations with NHS trusts.

Some of Tracey's frustrations and worries are an inevitable part of the life of a researcher. (Delays with obtaining the necessary ethical approvals and local governance approvals. Those weeks or months when you are convinced you're never going to find enough research participants or your response rate is too low, and the whole project will fail. Thank goodness for Tracey's flexibility and good nature.) Others were avoidable. The trouble with the payroll stemmed from a lack of clarity at HR about the fact that Tracey was seconded by her employer, as the recruitment process had been implemented as if it was an ordinary appointment. This led to Tracey being paid double (by her employer, and by the university) and took a while to untangle. Lessons were learnt.

Looking back, I have no regrets about appointing Tracey. Undoubtedly and perhaps inevitably, clinical nurses seconded to a research post need more supervision than more experienced researchers. It is important to ensure that research supervisors can make sufficient time for this. The success of the secondment also depends on the commitment and efforts of the nurse and the ' $f t^{\prime}$ ' with the research project. Our experience has been wholly positive, with benefits for Tracey, and benefits for me.

The benefits of gaining research experience for learning disability nurses

As a learning disability nurse I identified that I had very limited research experience. My skills and knowledge of conducting research were primarily as a student nurse, working on my dissertation, a literature review. I questioned myself when applying for the research post: was my experience relevant enough? On reflection, at this point, I had not truly taken into account or understood the impact of good quality evidence. The role as a research assistant has allowed me to build up more indepth skills in the gathering of data, analysis, discussions, development of academic papers and to write this article. I learnt to consider the importance of facts, figures, personal behaviours, feelings and attitudes. Hewitt (2007) recommends that research nurses are required to be sensitive to the needs of participants from the development of the research to the reporting of the findings. This allows nurses to fully address the moral complexity of research. Having developed my clinical skills since writing my dissertation as a student nurse, I am confident that I have refined more appropriate research skills, for example, a clearer understanding of what is required to critically analyse and comprehend pertinent information. 
Rose, T. \& Tuffrey-Wijne, I.

The benefits of gaining research experience through secondment Accepted for publication in Learning Disability Practice on $12^{\text {th }}$ December 2016 - This is not the version of record. Published version at http://journals.rcni.com/doi/10.7748/ldp.2017.e1800

It is the responsibility of all nurses to base their practice on the best available evidence (Nursing and Midwifery Council (NMC) 2015). For learning disability nurses this can be challenging, because the evidence base is limited within the area of learning disability (Parahoo et al 2000). More recently, Northway et al (2006) and Griffiths et al (2009) indicate that research activity in learning disability is increasing. However, it still remains imperative to improve practice in this field of nursing, with a need for investment in the quantity and quality of specific research.

This challenge was emphasised again by Northway et al (2015) who summarised that there is a desperate need to grow the research base within learning disability nursing. The report states that there is a significantly small amount of published data as to how research skills are taught to learning disability nurses. Northway et al (2015) continued to explore the opinions of both learning disability nurses and students with regards to the education received in research and evidence based practice. It highlighted the weak links between research and practice and the lack of support for the use of research within practice settings. The report concluded that to improve learning and the quality of service for people with learning disabilities this is an area which would need to develop.

From my experience there is a requirement for more opportunities for nurses to progress their research nursing skills through secondments. The $\operatorname{RCN}(2011,2014)$ highlights that continuing professional development needs and financial restrictions by employers mean that practitioners frequently have to self-fund and/or undertake education in their own time. There are continued concerns as to whether the workforce can retain a sufficient number of learning disability nurses with the right skill and knowledge mix to work across the range of settings. It is beneficial, therefore, to invest in nurses by promoting the opportunity of exciting new experiences through a secondment, to enhance skills, research and improve practice. In return, this will have an overall impact on the good quality care being delivered to people with learning disabilities. This was the first time either Irene or I had participated in a secondment and we both agree it has been a success. 
Rose, T. \& Tuffrey-Wijne, I.

The benefits of gaining research experience through secondment Accepted for publication in Learning Disability Practice on $12^{\text {th }}$ December 2016 - This is not the version of record. Published version at http://journals.rcni.com/doi/10.7748/ldp.2017.e1800

\section{References}

Clarke D and Copeland L (2003)Developing Nursing practice through work based learning Nurse Education in Practice(3) 236-244

Dryden H and Rice A (2008)Using guidelines to support secondment: a personal experience Journal of Nursing Management (16) 65-71

Griffiths P Bennett J and Smith J (2009)The size, extent and nature of the learning disability nursing research base: a systematic scoping review International Journal of Nursing Studies 46

(4) 490-507

Hamilton J and Wilkie C (2001)An appraisal of the use of secondment within a large teaching hospital Journal of Nursing Management 9 (6) 315-320

Hewitt J (2007) Ethical components of researcher-researched relationships in qualitative interviewing Qualitative Health Research 17 (8) 1149-1159

Northway R Mitchell D and Kaur-Mann K (2006)A Review of Learning Disability Nursing Research 1995-2003 University of Glamorgan

Northway R Parker M James N Davies L Johnson K and Wilson S (2015)Research teaching in learning disability nursing: Exploring the views of student and registered learning disability nurses Nurse Education Today (35) 1155-1160

Nursing and Midwifery Council (NMC) (2015) The CodeProfessional Standards of Practice and Behaviour for Nurses and MidwivesNMC London

Parahoo K Barr O and McCaughan E (2000) Research utilisation and attitudes towards research among learning disability nurse in Northern Ireland Journal of Advanced Nursing 31 (3) 607-613

Royal College of Nursing (RCN) (2011 updated 2014) Learning from the past-setting out the future:

Developing learning disability nursing in the United Kingdom An RCN position statement on the role of the learning disability nurse (accessed July 2016)

Royal College of Nursing (RCN) (2015) A workforce in crisis? The UK nursing labour market review 2015PDF Available at: https://www.rcn.org.uk/professionaldevelopment/publications/pub-005348 (accessed June 2016)

Thomas M and Hynes C (2009) The times they are a changing Journal of Nursing Management (17) $523-531$ 